\title{
Educating a New Generation in Congress: A Challenging Need
}

One of the trends in the U.S. Congress affecting the political and policy environment which has become apparent during the 104th Congress is the generational change in membership. While this trend has not been widely discussed in science circles, it should be of interest to the materials research community since it could have significant long-term implications for science and technology policy.

The recent turnover in the membership of Congress is such that new members (having less than three years of service) now constitute more than $50 \%$ of the House of Representatives. On the House Science Committee, which consists of 50 members, 22 are first-term representatives and nine are sophomores, meaning $62 \%$ of the committee has served for three years or less.

In general, new Science Committee members have little relevant education or experience to position them at the outset to engage fully in the debate over science policy. While this is not new, what is new is that the large number of new members now constitute a majority voting block. As a personal observation, new members generally take one to three congressional terms to achieve sufficient familiarity to independently engage in science policy debates; obviously it takes time to educate oneself on such complex issues.

While the U.S. Senate is lagging in this generational transition, in part because of its longer election cycle, this year"s Senate has already seen 13 announced retirements, the highest number in over 100 years. Clearly the trend of a generational transition is occurring there also.

Coupled with this growing generational transition are two additional factors which, when taken together, lead to serious implications. First, the Vannevar Bush social contract which has defined the interaction between science and the rest of society for the past 50 years may no longer be valid. This contract has been based on the propositions that scientific progress is essential to the national welfare; science provides a reservoir of knowledge that can be applied to national needs; and scientific progress results from the free intellectual pursuit by scientists of subjects of their choice. These assumptions, while perhaps still necessary, are no longer sufficient to sustain societal support in the post-cold war era. A national debate has been called for to define a new sustainable paradigm addressing in what ways science and technology contribute to the national welfare and how the troika of government and its laboratories, industry, and research universities can best work together to address our societal goals.

The second factor is a result of the fed-

\section{The New Age of $x-$ ray Microanalysis is here... the Age of Sapphire.}

\section{The Age of:}

\author{
* The best standard resolution of any EDS detector \\ * Sapphire reliability backed by a three-year warranty \\ * Optimum sensitivity with 20,000:1 peak-to-background ratio
}

Now leading in advanced detector technology, EDAX developed the Sapphire detectors for the 21st century, with performance standards beyond your expectations and as an instrument to help provide solutions to all your $x$-ray microanalysis problems.

With the Sapphire detectors you can do it all, without having to make compromises. It's a new age in x-ray microanalysis... the Age of Sapphire. Call EDAX today.

\section{Sapphire. A Shining Example of Peak Performance.}

91 McKee Drive Mahwah, NJ 07430-9978 Tel. Office: 201-529-4880 Fax: 201-529-3156
Ringbaan Noord 103, P.0. Box 4144 5004 JC Tilburg. The Netherlands Tel. Office: +31-13-5364000 Fax: $+31-13-5356279$
13-37, Kohnan 2-chome, Minato-ku Tokyo 108, Japan

Tel. Office: $81-3-3740-5172$

Fax: $81-3-3740-5190$

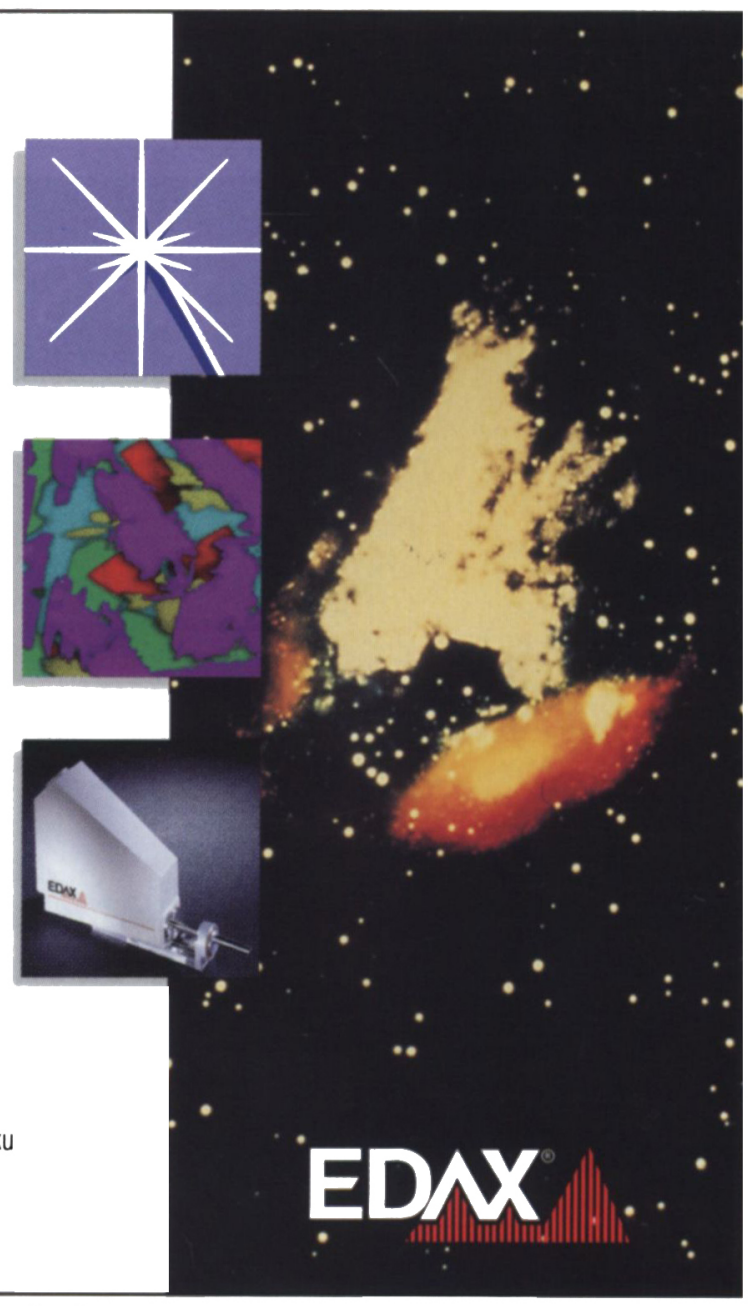

Circle No. 14 on Reader Service Card. 
eral budget trends. There have been eight successive years of declining federal support in inflation-adjusted dollars for research and development, extending through three presidential terms and five congressional terms, and amounting to an approximately $10 \%$ aggregate decrease to date. Under the most likely of the administration's current budget scenarios and those of the Congress, this declining trend will continue for six more years. The American Association for the Advancement of Science's (AAAS) projections from last year's budget resolution predicted an approximately one-third decline in nonmilitary federal $R \& D$ through 2002. Of course, the actual percentage will depend on the performance of the economy and many other factors. Thus, the debate in Washington is not over the direction of the aggregate federal R\&D support (which is continuing downward), but rather over the pace and the ratio of research versus development and military versus civilian support. The message is that science is being treated no differently, at this time at least, than any other discretionary program. However, the warning is that as the appropriations pie gets smaller and smaller for discre- tionary programs, science is competing directly with all other programs, many of which have strong advocacy groups skilled in congressional lobbying.

The issue then is how do these changes affect the materials community. There is a need for a continuing education program for new congressional members and their staffs on federal support for science as an investment. (A more general message is that all of our society must receive the same education.) While members often learn first from other members, then from the Washington establishment, and third from their constituent base, this third method has perhaps the longest term impact. Everyone involved must take part in crafting and delivering the relevant messages as "civic scientists." Constituentdelivered information is often the most effective, but all messages must reinforce and resonate if they are to have the desired impact. Site visits within a congressional member's district and visits with young researchers are particularly effective methods of delivery.

Also, I would caution against a discipline-by-discipline approach to arguments in support of science and technology. Rather, one needs to emphasize the broad nature of the investment. Most people believe federal spending in science and technology is an investment, but the difficult argument comes when one tries to decide how much is enough (or how much can be cut). Such issues do not have simple white paper answers and it is primarily through experience over years of involvement that congressional members arrive at the conclusion that this investment is critical, and develop their strong support for it.

In summary I believe the generational change in Congress is a new and significant change which is having a long-term effect on federal support for science and technology policy. I bring a clarion call to the materials research community to get involved in the education of Congress and our society on the critical nature of science and technology investments to the long-term benefit of this country.

THOMAS WEIMER

Thomas Weimer is Staff Director of the Basic Research Subcommittee, Committee on Science, in the U.S. House of Representatives. He can be reached at Subcommittee on Basic Research, B-374 Rayburn House Office Building, Washington, DC 20515.

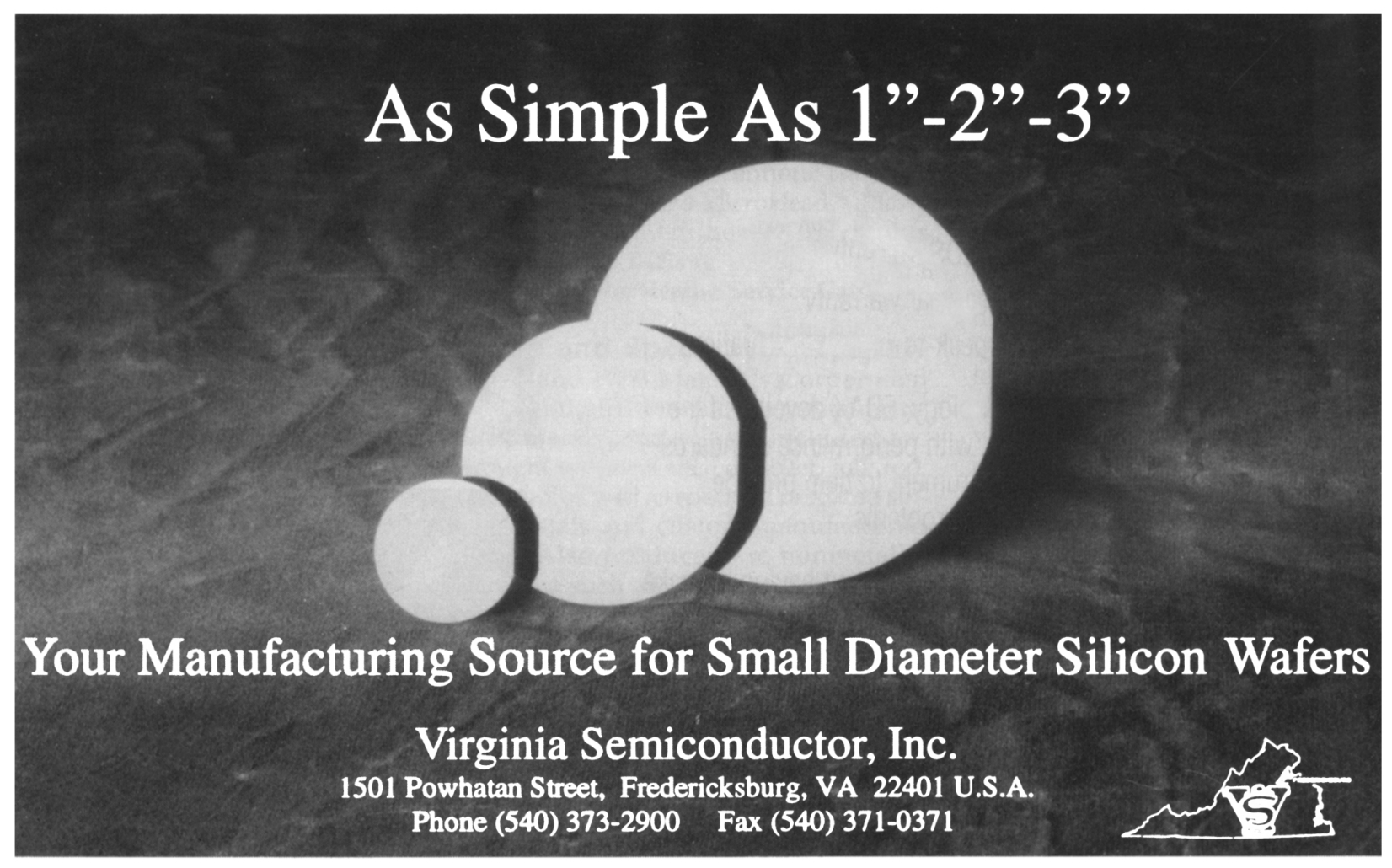

Circle No. 12 on Reader Service Card. 